\title{
openheart Echo-Doppler determinants of outcomes in patients with unoperated significant mitral regurgitation in current era
}

\author{
Asim M Rafique, ${ }^{1}$ Parham Zarrini, ${ }^{2}$ Nirmal Singh, ${ }^{3}$ Roy Beigel, ${ }^{4}$ Rigved Tadwalkar, ${ }^{1}$ \\ Meshe Chonde, ${ }^{5}$ Leandro Slipczuk, ${ }^{2}$ Bojan Cercek, ${ }^{2}$ Saibal Kar, $^{2}$ Robert J Siegel ${ }^{2}$
}

To cite: Rafique AM, Zarrini P, Singh N, et al. Echo-Doppler determinants of outcomes in patients with unoperated significant mitral regurgitation in current era. Open Heart 2016;3: $\mathrm{e} 000378$ doi:10.1136/openhrt-2015000378

- Additional material is available. To view please visit the journal online (http://dx. doi.org/10.1136/openhrt2015-000378)

Received 28 November 2015 Revised 19 April 2016 Accepted 7 June 2016

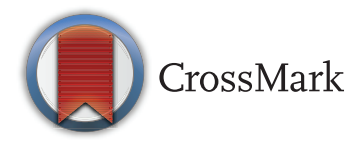

${ }^{1}$ UCLA Medical Center, Los Angeles, California, USA ${ }^{2}$ Cedars-Sinai Heart Institute, Los Angeles, California, USA ${ }^{3}$ University of Arizona, Tucson, Arizona, USA ${ }^{4}$ Sheba-Tel Hashomer Hospital, Ramat Gan, Israel ${ }^{5}$ UPMC Presbyterian, Pittsburgh, Pennsylvania, USA

Correspondence to Dr Robert J Siegel; siegel@cshs.org

\section{ABSTRACT}

Objective: One-half of patients with severe symptomatic mitral regurgitation (MR) do not undergo surgery due to comorbidities. We evaluated prognosticators of outcomes in patients with unoperated significant MR.

Methods: In this observational study, we retrospectively evaluated medical records of 75 consecutive patients with unoperated significant MR.

Results: All-cause mortality was $39 \%$ at 5 years. Non-survivors $(n=29)$ versus survivors $(n=46)$ were: older ( $77 \pm 9.8$ vs $68 \pm 14, p=0.006)$, had higher New York Heart Association (NYHA) class $(2.7 \pm 0.8$ vs $2.3 \pm 0.8, p=0.037$ ), higher brain natriuretic peptide ( $1157 \pm 717$ vs $427 \pm 502 \mathrm{pg} / \mathrm{mL}, \mathrm{p}=0.024, \mathrm{n}=18$ ), more coronary artery disease (61\% vs $35 \%, p=0.031)$, more frequent left ventricular ejection fraction $<50 \%(20.7 \%$ vs $4.3 \%, p=0.026)$, more functional MR ( $41 \%$ vs $22 \%$, $p=0.069)$, higher mitral $E / E^{\prime}(12.7 \pm 4.6$ vs $9.8 \pm 4$, $\mathrm{p}=0.008)$, higher pulmonary artery systolic pressure (PASP; $52.6 \pm 18.7$ vs $36.7 \pm 14, p<0.001$ ), more $\geq 3+$ tricuspid regurgitation ( $28 \%$ vs $4 \%, p=0.005$ ) and more right ventricular dysfunction ( $26 \%$ vs $6 \%$, $p=0.035)$. Significant predictors of 5 -year mortality were PASP $(p=0.001)$ and $E / E^{\prime}(p=0.011)$ using multivariate regression analysis.

Conclusions: Patients with unoperated significant MR have high mortality. Elevated PASP and mitral E/E' were the most significant predictors of 5-year survival in patients with unoperated significant MR. Current American College of Cardiology (ACC)/American Heart Association (AHA) guidelines provide a limited incorporation of echo-Doppler parameters in the preoperative risk stratification of patients with severe MR.

\section{INTRODUCTION}

Patients with uncorrected severe symptomatic mitral regurgitation (MR) have a significantly increased risk of morbidity and mortality. ${ }^{1-4}$ However, in the EuroHeart survey, approximately one-half of patients with severe symptomatic MR did not undergo surgery, most frequently due to comorbidities. ${ }^{5}$ However, there are no data from the current era, which addresses the natural history of

\section{KEY QUESTIONS}

What is already known about this subject?

- Patients with uncorrected severe symptomatic mitral regurgitation (MR) have a significantly increased risk of morbidity and mortality. Several clinical and echocardiographic prognosticators of outcomes in patients with unoperated severe MR have been described in the past, but limited data exist in the current era.

What does this study add?

- This study provides an updated analysis of echo-Doppler parameters in determining outcomes in patients with severe MR who are not candidates for surgery or percutaneous repair in the context of current American College of Cardiology (ACC)/American Heart Association (AHA) guidelines

How might this impact on clinical practice?

- This study will help clinicians to better risk stratify patients with severe MR and highlights that the current ACC/AHA guidelines provide limited incorporation of echo-Doppler parameters in the preoperative risk stratification of patients with severe MR.

patients with unoperated severe MR to determine the prognostic value of various echo-Doppler and clinical variables. The objective of our study was to identify clinical and echo-Doppler predictors of 5-year outcomes in patients with significant symptomatic MR who did not undergo surgical intervention in the current era.

\section{METHODS}

In this observational study, we retrospectively evaluated the medical records of consecutive patients with significant $\mathrm{MR}(\geq 3+)$ from December 2005 through December 2008, who were considered high risk and did not undergo surgery during a 5-year follow-up and were not deemed to be candidates for 
the MitraClip procedure. ${ }^{6} 7$ We excluded patients with concomitant moderate or greater aortic stenosis or aortic regurgitation, and patients with prior percutaneous or surgical repair or replacement of the mitral and/or aortic valves. ${ }^{6} 7$ Hospital medical records and the social security death index were used to obtain and verify the 5-year mortality data. Patients were stratified into two groups as survivors versus non-survivors at 5 years of follow-up. The Institutional Review Board approved the study, and the waiver for patient consent was granted because of the retrospective nature of the study.

Two independent reviewers (RJS and AMR) evaluated the echocardiograms. Significant MR was defined as per the ACC/AHA guidelines, using a combination of qualitative and quantitative parameters including MR colour jet area to left atrial area ratio (JA/LAA) $\geq 40 \%$, Doppler vena contracta width (VC) $\geq 0.7 \mathrm{~cm}$, mitral regurgitant volume (Rvol) $\geq 60 \mathrm{~mL} /$ beat, regurgitant fraction $\geq 50 \%$, effective regurgitant orifice area (EROA) $\geq 40 \mathrm{~mm}^{2}$, density and width of MR continuous wave $(\mathrm{CW})$ jet, pulmonary vein flow (PVF) with systolic reversal, and enlarged left atrium (LA) and left ventricle (LV).$^{6-8}$

Transmitral early (E) peak velocity, its deceleration time (DT) and transmitral atrial (A) wave velocity were obtained with a pulsed wave sample at the tip of the mitral valve. ${ }^{9}$ Early diastolic velocity of the lateral aspect of the mitral annulus ( $\left.\mathrm{E}^{\prime}\right)$ was measured by Doppler tissue imaging (TDI). PVF was obtained on an apical four-chamber view. ${ }^{9} 10$

The maximum velocity of the tricuspid regurgitation (TR) jet was measured using CW Doppler as per American Society of Echocardiography (ASE) recommendations. ${ }^{8} 11$ Right ventricle (RV) systolic pressure was estimated based on the modified Bernoulli equation and assumed to be equal to the pulmonary artery systolic pressure (PASP) in the absence of RV outflow obstruction. PASP was calculated by adding the tricuspid valve pressure gradient to the estimated right atrial pressure (RAP). ${ }^{11}$ RAP was considered as: $3 \mathrm{~mm} \mathrm{Hg}$ for inferior vena cava (IVC) diameter $<1.7 \mathrm{~cm}$ and $\geq 50 \%$ collapse with inspiration; $7 \mathrm{~mm} \mathrm{Hg}$ for IVC diameter $\geq 1.7 \mathrm{~cm}$ and $\geq 50 \%$ decrease in the diameter with inspiration; $12 \mathrm{~mm} \mathrm{Hg}$ if $<50 \%$ collapse on inspiration; $\geq 15 \mathrm{~mm} \mathrm{Hg}$ if the IVC was dilated without any collapse. ${ }^{8} 11$

\section{Statistical analysis}

Statistical analysis was performed with the statistical software program IBM SPSS V.21.0 (IBM Inc). Continuous data were presented as mean \pm SD. Categorical data were presented as an absolute number or percentages. Between-groups comparisons of baseline data were performed using the independent-samples t-test. All categorical variables were compared between the two groups using the Pearson $\chi^{2}$ test. Clinical and statistical variables were entered into Cox regression models to evaluate the independent predictors of 5-year survival.
Kaplan-Meier analysis was used to estimate survival. The log-rank test was used to compare survival across two groups. A $p$ value $<0.05$ was considered statistically significant. Given the retrospective and observational nature of the study, the sample size was not calculated.

\section{RESULTS}

Medical records of 83 patients with significant MR and available 5-year follow-up data were reviewed. Eight patients were excluded due to: prior mitral valve repair (MVR; $n=2$ ), MitraClip treatment $(n=1)$, or MVR/mitral valve replacement (MVRe; $n=3$ ) during the follow-up period, or absence of a reliable TR signal on echocardiography $(n=2)$. We included 75 patients (45 male) with a mean age of $72 \pm 11$ years. The mean mitral EROA was $54 \pm 30 \mathrm{~mm}^{2}$, the mitral Rvol was $80 \pm 37 \mathrm{~mL} /$ beat, the VC was $0.6 \pm 0.2 \mathrm{~cm}$ and the mean mitral JA/LAA was 42.3 $\pm 12 \mathrm{~mm} \mathrm{Hg}$. TDI of the lateral mitral annulus was available for $64(85 \%)$ patients, and PVF was interpretable in $62(83 \%)$ patients. The reasons for non-operability are shown in table 1.

Overall, $29(39 \%)$ patients died during the 5 years of follow-up. As shown in table 2, non-survivors $(\mathrm{n}=29)$ compared with survivors $(\mathrm{n}=46)$ were older $(77 \pm 9.8$ vs 68 \pm 14 years, $\mathrm{p}=0.006$ ); had more coronary artery disease $(61 \%$ vs $35 \%, \mathrm{p}=0.031)$, diabetes $(21 \%$ vs $6.5 \%$, $\mathrm{p}=0.057)$, pulmonary hypertension $(71 \%$ vs $37 \%$, $\mathrm{p}=0.004)$, atrioventricular block ( $14 \%$ vs $2.3 \%, \mathrm{p}=0.073$ ), higher New York Heart Association (NYHA) class (2.7 \pm 0.8 vs $2.3 \pm 0.8, \quad \mathrm{p}=0.037$ ), higher brain natriuretic peptide (BNP) level $(1157 \pm 717$ vs $427 \pm 502, \mathrm{p}=0.024$, $\mathrm{n}=18$ ) and a trend for a higher incidence of syncope $(7.1 \%$ vs $0 \%, p=0.066)$. Overall, there was no significant difference in the prevalence of symptoms between the two study groups $(93.1 \%$ vs $84.8 \%, \mathrm{p}=0.281)$. Other comorbidities and medical treatment were comparable between the two groups.

Table 1 Reasons for not performing mitral valve surgery

Variable

n

Advanced age $\geq 90$ years

Frailty

Severe mitral calcification

Redo surgery

Severe PVD

Poor bypass targets

Severe kyphosis

Malignancy

Other comorbidities*

Other reasons $\dagger$

*Other comorbidities included infection, gastrointestinal bleeding

(GIB), cirrhosis, severe COPD, vasculitis.

tOther reasons included non-compliance, patient preference

$(n=17)$, lost to follow-up $(n=9)$ or no obvious reason $(n=3)$.

COPD, chronic obstructive pulmonary disease; PVD, peripheral

vascular disease. 
Table 2 Comparison of baseline clinical variables between non-survivors and survivors

\begin{tabular}{|c|c|c|c|}
\hline Variable & Non-survivors mean $\pm S D(n=29)$ & Survivors mean $\pm S D(n=46)$ & p Value \\
\hline Age (years) ${ }^{\star}$ & $76.7 \pm 9.8$ & $68.2 \pm 14$ & 0.006 \\
\hline Gender (female) & $38 \%$ & $41 \%$ & 0.772 \\
\hline BSA $\left(m^{2}\right)$ & $1.8 \pm 0.3$ & $1.8 \pm 0.2$ & 0.696 \\
\hline SBP $(\mathrm{mm} \mathrm{Hg})$ & $124 \pm 19$ & $126 \pm 22$ & 0.804 \\
\hline \multicolumn{4}{|l|}{ Symptoms } \\
\hline Angina & $10.7 \%$ & $8.7 \%$ & 0.774 \\
\hline Dyspnoea & $85.7 \%$ & $82.6 \%$ & 0.725 \\
\hline NYHA class* & $2.7 \pm 0.8$ & $2.3 \pm 0.8$ & 0.037 \\
\hline \multicolumn{4}{|l|}{ Cardiovascular risk factors } \\
\hline Diabetes mellitus* & $21 \%$ & $6.5 \%$ & 0.057 \\
\hline Hypertension & $71.4 \%$ & $65.2 \%$ & 0.581 \\
\hline \multicolumn{4}{|l|}{ Cardiovascular comorbidities } \\
\hline $\mathrm{CHF}$ & $89.3 \%$ & $82.6 \%$ & 0.434 \\
\hline $\mathrm{CAD}^{*}$ & $60.7 \%$ & $34.8 \%$ & 0.031 \\
\hline Previous MI & $25 \%$ & $19.6 \%$ & 0.582 \\
\hline Atrialfibrillation/flutter & $44 \%$ & $30 \%$ & 0.228 \\
\hline CVA & $7.1 \%$ & $6.5 \%$ & 0.918 \\
\hline PVD & $14.3 \%$ & $4.3 \%$ & 0.129 \\
\hline Pacemaker & $22.2 \%$ & $13 \%$ & 0.307 \\
\hline Pulmonary hypertension* & $71.4 \%$ & $37 \%$ & 0.004 \\
\hline \multicolumn{4}{|l|}{ Non-cardiac comorbidities } \\
\hline $\mathrm{CKD} \pm$ dialysis & $35.7 \%$ & $19.6 \%$ & 0.123 \\
\hline COPD & $14.3 \%$ & $6.5 \%$ & 0.268 \\
\hline Cancer & $25 \%$ & $10.9 \%$ & 0.111 \\
\hline \multicolumn{4}{|l|}{ Medications } \\
\hline Aspirin & $60.9 \%$ & $52.6 \%$ & 0.531 \\
\hline$\beta$-Blockers & $64 \%$ & $46.20 \%$ & 0.163 \\
\hline ACEi/ARB & $72 \%$ & $56.8 \%$ & 0.211 \\
\hline Statins & $57.7 \%$ & $50 \%$ & 0.545 \\
\hline Vasodilators $\dagger$ & $21 \%$ & $29 \%$ & 0.477 \\
\hline Diuretics $\ddagger$ & $67 \%$ & $57 \%$ & 0.439 \\
\hline Digoxin & $36 \%$ & $21.1 \%$ & 0.191 \\
\hline Coumadin & $37.50 \%$ & $27 \%$ & 0.388 \\
\hline Antiarrhythmics & $16 \%$ & $18.9 \%$ & 0.768 \\
\hline \multicolumn{4}{|l|}{ Laboratory } \\
\hline Sodium (mmol/L) & $138 \pm 6$ & $141 \pm 3$ & 0.093 \\
\hline Creatinine (mg/dL) & $2.1 \pm 2.8$ & $1.9 \pm 2.5$ & 0.852 \\
\hline Haemoglobin (g/dL) & $12.5 \pm 1.4$ & $13.1 \pm 1.8$ & 0.231 \\
\hline Platelet counts $(1000 / \mu \mathrm{L})$ & $224 \pm 56$ & $229 \pm 94$ & 0.851 \\
\hline INR & $1.5 \pm 0.4$ & $1.3 \pm 0.6$ & 0.341 \\
\hline LDL (mg/dL) & $69.4 \pm 34.9$ & $80.3 \pm 42.3$ & 0.546 \\
\hline BNP $(\mathrm{pg} / \mathrm{mL})^{*}$ & $1158 \pm 717$ & $427 \pm 503$ & 0.024 \\
\hline $\mathrm{HbA} 1 \mathrm{c}(\%)$ & $7.1 \pm 1.7$ & $5.4 \pm 0.2$ & 0.22 \\
\hline \multicolumn{4}{|c|}{$\begin{array}{l}{ }^{*} \mathrm{p}<0.05 . \\
\text { †Vasodilators included calcium channel blockers, } \alpha \text {-blockers, hydralazine and nitrates. } \\
\text { fDiuretics included Lasix, thiazides, spironolactone. } \\
\text { ACEi, ACE inhibitors; ARB, angiotensin receptor blocker; BNP, brain natriuretic peptide; BSA, body surface area; CAD, coronary artery } \\
\text { disease; CHF, congestive heart failure; CKD, chronic kidney disease; COPD, chronic obstructive pulmonary disease; CVA, cerebral vascular } \\
\text { accident; HbA1c, glycated haemoglobin; INR, international normalised ratio; LDL, low-density lipoprotein; MI, myocardial infarction; } \\
\text { NYHA, New York Heart Association; PVD, peripheral vascular disease; SBP, systolic blood pressure. }\end{array}$} \\
\hline
\end{tabular}

The use of $\beta$-blockers, ACE inhibitors or angiotensin receptor blockers, or spironolactone was significantly higher in non-survivors compared with survivors $(87 \%$ vs $61 \%, \mathrm{p}=0.033)$. The use of these medications tended to be more frequent in non-survivors compared with survivors both in functional MR (FMR; $100 \%$ vs $78 \%$, $\mathrm{p}=0.134$ ) and degenerative MR (DMR; $79 \%$ vs $56 \%$, $\mathrm{p}=0.147)$. Patients on these medications tended to have worse: NYHA class $(2.6 \pm 0.7$ vs $2.1 \pm 0.9, \mathrm{p}=0.044)$, left ventricular ejection fraction (LVEF; $58 \pm 17 \%$ vs $65 \pm 12 \%$, $\mathrm{p}=0.182)$, forward stroke volumes $(47 \pm 19$ vs $71 \pm 42$, $\mathrm{p}=0.051)$, PASP $(43 \pm 16$ vs $36 \pm 16, \mathrm{p}=0.176)$, RAP ( $9 \pm 6$ vs $8 \pm 6, \mathrm{p}=0.782)$, BNP $(896 \pm 1232$ vs $491 \pm 195, \mathrm{p}=0.561)$ and creatinine $(2.1 \pm 2.9$ vs $1.0 \pm 0.4, \mathrm{p}=0.289)$. 
Table 3 Comparison of echocardiographic variables between non-survivors and survivors

\begin{tabular}{|c|c|c|c|}
\hline & Non-survivors mean $\pm S D(n=29)$ & Survivors mean $\pm S D(n=46)$ & p Value \\
\hline LVEDD (mm) & $55.5 \pm 9.7$ & $53.6 \pm 6.8$ & 0.369 \\
\hline LV mass $(g)$ & $243 \pm 111$ & $246 \pm 107$ & 0.89 \\
\hline LVESV (mL) & $52.7 \pm 41.4$ & $38.4 \pm 33.6$ & 0.105 \\
\hline LVEDV (mL) & $102 \pm 48$ & $105 \pm 65$ & 0.839 \\
\hline LVEF (\%) & $54 \pm 20$ & $59 \pm 15$ & 0.243 \\
\hline LVOT VTI (cm) & $15 \pm 4.4$ & $16.2 \pm 4$ & 0.247 \\
\hline $3+$ TR grade $(\%)^{\star}$ & $28 \%$ & $4 \%$ & 0.0045 \\
\hline RV dysfunction (\%)* & $26 \%$ & $6 \%$ & 0.0351 \\
\hline MV E velocity $(\mathrm{cm} / \mathrm{s})^{*}$ & $116 \pm 29$ & $100 \pm 31$ & 0.024 \\
\hline MV E/A & $1.7 \pm 0.9$ & $1.5 \pm 0.6$ & 0.296 \\
\hline MV DT (ms) & $188 \pm 59$ & $203 \pm 62$ & 0.301 \\
\hline $\mathrm{MV} E / \mathrm{E}^{\prime}$ * & $12.7 \pm 4.6$ & $9.8 \pm 4$ & 0.008 \\
\hline$E / E^{\prime} \geq 15^{*}$ & $32 \%$ & $10.5 \%$ & 0.034 \\
\hline $\operatorname{LAA}\left(\mathrm{cm}^{2}\right)$ & $24.9 \pm 6.4$ & $26.8 \pm 7.7$ & 0.285 \\
\hline PASP systolic $(\mathrm{mm} \mathrm{Hg})^{*}$ & $52.6 \pm 18.7$ & $36.7 \pm 14$ & $<0.001$ \\
\hline$P A S P \geq 50 \mathrm{~mm} \mathrm{Hg}$ & $58.6 \%$ & $13.3 \%$ & $<0.001$ \\
\hline $\operatorname{RAP}(\overline{m m ~ H g})^{\star}$ & $10.6 \pm 6.5$ & $7.7 \pm 4.6$ & 0.042 \\
\hline
\end{tabular}

${ }^{*} \mathrm{p}<0.05$.

DT, deceleration time; EDD, end diastolic dimension; EDV, end diastolic volume; EF, ejection fraction; ESD, end systolic dimension; ESV, end systolic volume; IVS, interventricular septum; LAA, left atrial area; LV, left ventricle; LVOT, left ventricular outflow tract; MV, mitral valve; PASP, pulmonary artery systolic pressure; PV, pulmonary vein; PWT, posterior wall thickness; RAP, estimated right atrial pressure; RV, right ventricle; TR, tricuspid regurgitation; VTI, velocity time integral.

Table 4 Comparison of echocardiographic variables related to MV anatomy and function

\begin{tabular}{|c|c|c|c|}
\hline & Non-survivors mean $\pm S D(n=29)$ & Survivors mean $\pm S D(n=46)$ & p Value \\
\hline MV VC (cm) & $0.61 \pm 0.15$ & $0.57 \pm 0.14$ & 0.213 \\
\hline MV JA/LAA (\%)* & $0.48 \pm 0.14$ & $0.39 \pm 0.1$ & 0.001 \\
\hline PISA radius $(\mathrm{cm})$ & $0.99 \pm 0.24$ & $1.09 \pm 0.26$ & 0.091 \\
\hline $\operatorname{Vr}(\mathrm{cm} / \mathrm{s})$ & $36.3 \pm 2.5$ & $36.9 \pm 4.5$ & 0.535 \\
\hline $\operatorname{MR} \operatorname{Vmax}(\mathrm{m} / \mathrm{s})$ & $5.08 \pm 0.79$ & $4.99 \pm 0.75$ & 0.615 \\
\hline MR VTI (cm) & $160.1 \pm 25.8$ & $155.9 \pm 38.2$ & 0.604 \\
\hline $\operatorname{EROA}\left(\mathrm{mm}^{2}\right)$ & $46.7 \pm 23$ & $59.2 \pm 32.3$ & 0.074 \\
\hline MR Rvol (mL/beat) & $73.2 \pm 33.9$ & $83.4 \pm 38.7$ & 0.249 \\
\hline MR RF (\%) & $59 \pm 11 \%$ & $56 \pm 15 \%$ & 0.511 \\
\hline Abnormal PV flow (\%) & $48 \%$ & $54 \%$ & 0.639 \\
\hline MR functional (\%) & $41 \%$ & $22 \%$ & 0.069 \\
\hline MR eccentric (\%) & $64 \%$ & $78 \%$ & 0.242 \\
\hline Annular calcification (\%)* & $70 \%$ & $36 \%$ & 0.021 \\
\hline
\end{tabular}

${ }^{*} \mathrm{p}<0.05$.

EROA, effective regurgitant orifice area; JA/LAA, ratio of jet area to left atrial area; MR, mitral regurgitation; MV, mitral valve; PV, pulmonary vein; PISA, proximal isovelocity surface area; RF, regurgitant fraction; Rvol, regurgitant volume; VC, vena contracta; VFR, volume flow rate; $\mathrm{Vr}$, aliasing velocity at the radial distance $\mathrm{r}(\mathrm{cm} / \mathrm{s})(\mathrm{Vr})$; VTI, velocity time integral.

As shown in table 3, non-survivors compared with survivors had: similar LV systolic $(36.4 \pm 13.1$ vs $34.3 \pm 9.2$, $\mathrm{p}=0.448)$ and $\mathrm{LV}$ diastolic (55.5 \pm 9.7 vs $53.6 \pm 6.8, \mathrm{p}=0.369)$ dimensions, with a higher prevalence of an $\mathrm{LVEF}<50 \%$ ( $20.7 \%$ vs $4.3 \%, \mathrm{p}=0.026)$, lower $\mathrm{LV}$ stroke volume $(49.5$ \pm 21.8 vs $66.7 \pm 47.8, \mathrm{p}=0.038)$, higher mitral $\mathrm{E}$ velocity $(116.1 \pm 28.9$ vs $99.5 \pm 30.7, \quad \mathrm{p}=0.024)$, higher $\mathrm{E} / \mathrm{E}^{\prime}$ $(12.7 \pm 4.6$ vs $9.8 \pm 4, \mathrm{p}=0.008)$, higher prevalence of $\mathrm{E} /$ $\mathrm{E}^{\prime} \geq 15$ (32\% vs $\left.10.5 \%, \mathrm{p}=0.034\right)$, higher PASP $(52.6 \pm 18.7$ vs $36.7 \pm 14, \mathrm{p}<0.001)$, similar $\mathrm{E} / \mathrm{A} \geq 2 \quad(18.2 \%$ vs $26.3 \%$, $\mathrm{p}=0.473)$, similar $\mathrm{DT}<140 \mathrm{~ms}(21.4 \%$ vs $10.9 \%, \mathrm{p}=0.216)$, and more TR and RV dysfunction ( $26 \%$ vs $4 \%, \mathrm{p}=0.035)$.
Non-survivors compared with survivors had: severe MR (72\% vs $70 \%, \mathrm{p}=0.791$ ), FMR ( $41 \%$ vs $22 \%, \mathrm{p}=0.069)$, eccentric MR jet $(64 \%$ vs $78 \%, \mathrm{p}=0.242)$, mitral annular calcification $(70 \%$ vs $36 \%, \mathrm{p}=0.021)$, JA/LAA $(72.4 \%$ vs $45.7 \%$, p 0.023$), \mathrm{VC} \geq 0.7(34.5 \%$ vs $22.2 \%, \mathrm{p}=0.246)$, Rvol $\geq 60 \mathrm{~mL}(58.6 \%$ vs $76.1 \%, \mathrm{p}=0.11)$, EROA $\geq 40 \mathrm{~mm}^{2}$ $(51.7 \%$ vs $76.1 \%, \mathrm{p}=0.029)$ and mean EROA $(47 \pm 23$ vs $59 \pm 32, \mathrm{p}=0.074$; table 4 ). Of the 22 patients with FMR, the 5 -year mortality was $54 \%$ compared with $32 \%$ of 53 patients with DMR $(\mathrm{p}=0.032)$.

Figure 1 shows the areas under the curve (AUC) from receiver-operator characteristic curve for the various 

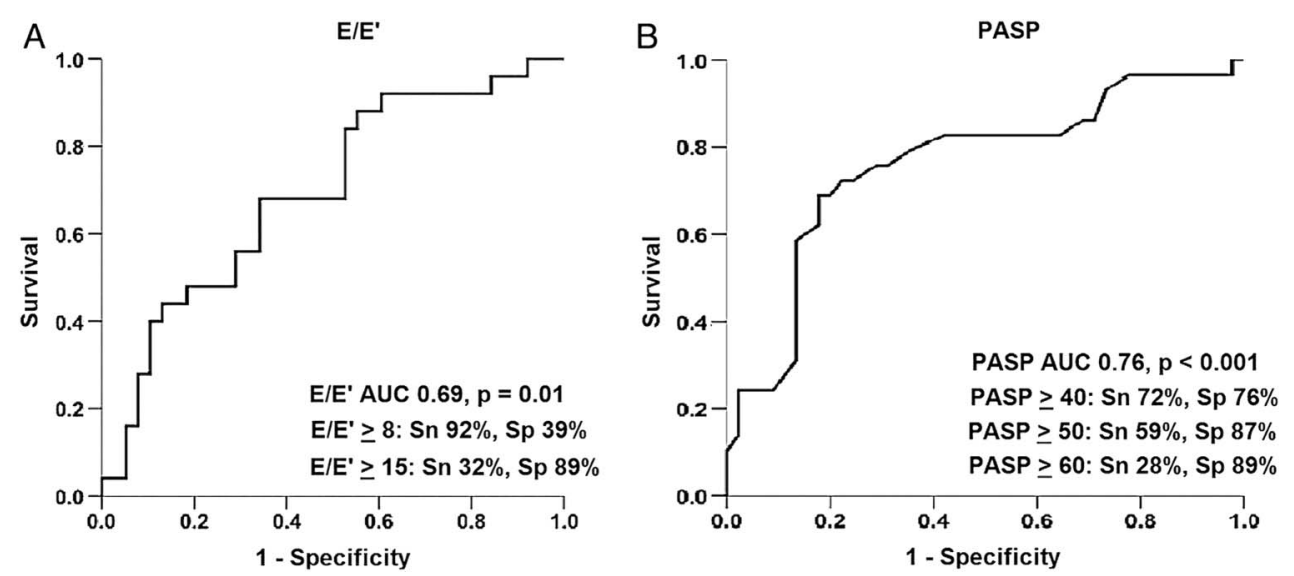

Figure 1 (A) ROC for the prediction of 5-year mortality in unoperated significant MR. AUCs and corresponding $p$ values are shown for lateral annulus $E / E^{\prime}(A \cup C=0.69,95 \% \mathrm{Cl} 0.56$ to $0.83, p=0.01$ ). (B) ROC for the prediction of 5 -year mortality in unoperated significant MR. AUCs and corresponding $p$ values are shown for PASP (AUC=0.76, $95 \% \mathrm{Cl} 0.64$ to $0.88, p<0.001$ ). AUC, area under curve; PASP, pulmonary artery systolic pressure; ROC, receiver-operator characteristic curve.
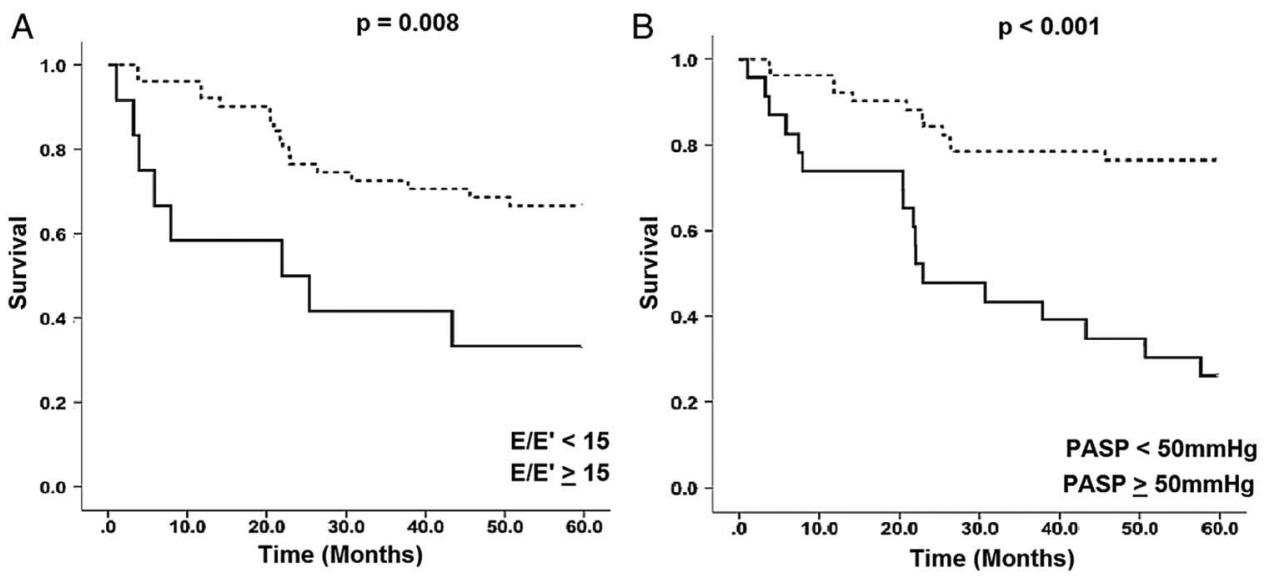

Figure 2 (A): Five-year mortality in unoperated patients with severe $M R$ with $E / E^{\prime} \geq 15$ was significantly higher compared with patients with $E / E^{\prime}<15$ (67\% vs $\left.33 \%, p=0.008\right)$. (B): Five-year mortality in unoperated patients with severe MR with $P A S P \geq 50$ was significantly higher compared with patients with $\mathrm{PASP}<50$ (76\% vs $23 \%, \mathrm{p}<0.001)$. DMR, degenerative MR; $\mathrm{EROA}$, effective regurgitant orifice area; FMR, functional MR; MR, mitral regurgitation; PASP, pulmonary artery systolic pressure.

parameters. Lateral $\mathrm{E} / \mathrm{E}^{\prime} \geq 8$ was $92 \%$ sensitive and $39 \%$ specific; lateral $\mathrm{E} / \mathrm{E}^{\prime} \geq 15$ was $32 \%$ sensitive and $89 \%$ specific; $\mathrm{PASP} \geq 50 \mathrm{~mm} \mathrm{Hg}$ was $59 \%$ sensitive and $87 \%$ specific; PASP $\geq 60 \mathrm{~mm} \mathrm{Hg}$ was $28 \%$ sensitive and $89 \%$ specific; RAP $\geq 10 \mathrm{~mm} \mathrm{Hg}$ was $36 \%$ sensitive and $81 \%$ specific ( $\mathrm{AUC}=0.62,95 \%$ CI 0.48 to $0.76, \mathrm{p}=0.098$ ); mitral $\mathrm{E}$ velocity $\geq 120 \mathrm{~cm} / \mathrm{s}$ was $43 \%$ sensitive and $80 \%$ specific (AUC $0.66,95 \%$ CI 0.53 to $0.78, \mathrm{p}=0.027$ ); and mitral JA/LAA $\geq 40 \%$ was $66 \%$ sensitive and $60 \%$ specific (AUC $0.71,95 \%$ CI 0.60 to $0.83, \mathrm{p}<0.01$ ) to predict 5 -year mortality.

Using Kaplan-Meier curves, the 5-year all-cause mortality was $67 \%$ in patients with $\mathrm{E} / \mathrm{E} \geq 15$ compared with $33 \%$ in patients with $\mathrm{E} / \mathrm{E}^{\prime}<15 \quad(\mathrm{p}=0.008$, figure $2 \mathrm{~A})$. Using Kaplan-Meier curves, the 5-year mortality was $74 \%$ for patients with a PASP $\geq 50 \mathrm{~mm} \mathrm{Hg}$ compared with $23 \%$ for patients with $\mathrm{PASP}<50 \mathrm{~mm} \mathrm{Hg}(\mathrm{p}<0.001$, figure 2B).

Patients with $\mathrm{PASP} \geq 50 \mathrm{~mm} \mathrm{Hg}$ and $\mathrm{E} / \mathrm{E}^{\prime} \geq 15 \quad(\mathrm{n}=8)$ had a 5-year mortality of $75 \%$ while patients with $\mathrm{PASP}<50 \mathrm{~mm} \mathrm{Hg}$ and $\mathrm{E} / \mathrm{E}^{\prime}<15 \quad(\mathrm{n}=38)$ had a lower 5-year mortality of $21 \%$. Only seven patients had LVEF $<50 \%$, so further stratification was not possible. In the subgroup of patients with $L V E F \geq 50 \%$, patients with $\mathrm{PASP} \geq 50 \mathrm{~mm} \mathrm{Hg}$ had a significantly worse survival than patients with PASP $<50 \mathrm{~mm} \mathrm{Hg}$ (22\% vs $67 \%, \mathrm{p}<0.001$ ).

In the multivariate Cox regression analysis presented in table 5 , the only significant predictor predictive of 5 -year mortality was a PASP $\geq 50 \mathrm{~mm} \mathrm{Hg}$ (HR 2.2, 95\% CI 1.4 to $3.3, \mathrm{p}<0.001)$. Age, gender, NYHA class $\geq 3$, $\mathrm{LVEF}<50 \%, \quad \mathrm{E} / \mathrm{E}^{\prime} \geq 15, \quad \mathrm{EROA} \geq 40$ and $\mathrm{MR} \quad \mathrm{Rvol} \geq 60$, aetiology were not significant independent predictors in the multivariate model. Using the above parameters as continuous variables in the linear regression model, the significant predictors included PASP $(\mathrm{p}=0.001)$ and $\mathrm{E} / \mathrm{E}^{\prime}(\mathrm{p}=0.011)$.

\section{DISCUSSION}

Patients with moderate to severe or severe MR who do not undergo surgical repair or replacement because of 
Table 5 Cox regression model using clinical and echocardiographic variables

\begin{tabular}{|c|c|c|c|c|}
\hline & HR & $95 \% \mathrm{Cl}$ & $\begin{array}{l}\text { Univariate } \\
\text { p Value }\end{array}$ & $\begin{array}{l}\text { Multivariate } \\
\text { p Value }\end{array}$ \\
\hline PASP $\geq 50(\mathrm{~mm} \mathrm{Hg})^{*}$ & 2.2 & 1.41 to 3.34 & $<0.001$ & $<0.001$ \\
\hline$E / E^{\prime} \geq 15$ & 0.96 & 0.27 to 3.44 & 0.034 & 0.948 \\
\hline $\mathrm{JA} / \mathrm{LA} A \geq 40 \%$ & 2.24 & 0.87 to 5.79 & 0.023 & 0.128 \\
\hline $\mathrm{RV} \geq 60$ (mL/beat) & 1.09 & 0.12 to 10.2 & 0.11 & 0.942 \\
\hline$E R O A \geq 40\left(\mathrm{~mm}^{2}\right)$ & 0.87 & 0.09 to 8.54 & 0.029 & 0.917 \\
\hline LVEF <50 (\%) & 2.83 & 0.79 to 10.2 & 0.026 & 0.112 \\
\hline NYHA class $\geq 3$ & 0.66 & 0.21 to 2.04 & 0.085 & 0.466 \\
\hline Gender (male) & 1.23 & 0.43 to 3.53 & 0.772 & 0.706 \\
\hline Age (years) & 1.04 & 1.00 to 1.02 & 0.006 & 0.047 \\
\hline
\end{tabular}

comorbidities have a high 5-year mortality. In the multivariate analysis, significant predictors of 5-year mortality were PASP and E/E'. We did not find EROA, Rvol and VC to be predictive of mortality in patients with significant MR.

The likely mechanisms of increased mortality in patients with elevated and persistent PASP most likely include more advanced LV and LA remodelling in response to chronic volume overload from severe MR resulting in irreversible changes in the myocardium due to fibrosis and the permanent dysfunction of endothelium in the pulmonary vasculature. Elevated filling parameters in the setting of pulmonary hypertension therefore represent a more advanced disease stage where early intervention is warranted. Early optimisation of medical therapy for congestive heart failure (CHF) is prudent to improve pulmonary hypertension $(\mathrm{PH})$ and hence outcomes in patients with MR by preventing late LV irreversible remodelling. ${ }^{12}$ The role of specific therapy for $\mathrm{PH}$ should be evaluated in patients with MR with an elevated transpulmonary gradient. MVR/MVRe is now an alternative treatment for patients with severe symptomatic MR who are not operative candidates. ${ }^{13-15}$ It is important to carefully evaluate the patients undergoing MVR/ MVRe or MitraClip as increasingly more complex and sick patients are being referred for these procedures. ${ }^{16-18}$ Swaans et al ${ }^{19}$ showed that high surgical-risk patients with severe symptomatic MR treated with transcatheter MV repair show similar survival rates comparable to patients undergoing surgery, with both groups showing a survival benefit compared with conservative treatment. Appropriate risk stratification and proper selection of these high-risk patients and optimisation of filling pressures may improve outcomes of these patients with poor surgical options and with an increased mortality with medical therapy alone.

\section{CONCLUSIONS}

Patients with unoperated significant MR have a high mortality rate. Elevated filling pressures as determined by PASP and mitral $\mathrm{E} / \mathrm{E}^{\prime}$ were most significant predictors of 5-year survival in patients with unoperated significant MR. Optimisation of filling pressure preprocedure or earlier intervention preceding development of irreversible changes may further improve outcomes in patients undergoing evaluation for MVR/MVRe or MitraClip.

\section{Limitations}

This is a retrospective study; however, few studies have evaluated the prognosis of untreated MR in the modern era as most patients with severe MR undergo surgery or percutaneous intervention. This study is unique in providing an updated evaluation of echo-Doppler prognosticators in patients with severe MR. PASP was evaluated using echocardiography, which reflects the filling pressure under true resting conditions, avoiding the impact of analgesia or sedation and intravenous fluids on cardiac haemodynamics.

Contributors AMR and RJS contributed to the conception and design of the study. Data were collected by AMR, PZ, NS, RT and MC. Statistical analysis and interpretation of data were performed by AMR, RJS and RB. The manuscript was drafted by AMR with further revisions by RJS, BC and SK for important intellectual content.

Funding This research received no grant from any funding agency in the public, commercial or not-for-profit sector.

Competing interests None declared.

Ethics approval Cedars-Sinai Institutional Review Board (IRB).

Provenance and peer review Not commissioned; externally peer reviewed. Data sharing statement No additional data are available.

Open Access This is an Open Access article distributed in accordance with the Creative Commons Attribution Non Commercial (CC BY-NC 4.0) license, which permits others to distribute, remix, adapt, build upon this work noncommercially, and license their derivative works on different terms, provided the original work is properly cited and the use is non-commercial. See: http:// creativecommons.org/licenses/by-nc/4.0/

\section{REFERENCES}

1. Nishimura RA, Otto CM, Bonow RO, et al., American College of Cardiology/American Heart Association Task Force on Practice Guidelines. 2014 AHA/ACC guideline for the management of patients with valvular heart disease: executive summary: a report of 
the American College of Cardiology/American Heart Association Task Force on Practice Guidelines. J Am Coll Cardiol 2014;63:2438-88.

2. Delahaye JP, Gare JP, Viguier E, et al. Natural history of severe mitral regurgitation. Eur Heart J 1991;12(Suppl B):5-9.

3. Rosen SE, Borer JS, Hochreiter C, et al. Natural history of the asymptomatic/minimally symptomatic patient with severe mitral regurgitation secondary to mitral valve prolapse and normal right and left ventricular performance. Am J Cardiol 1994;74:374-80.

4. Hannan EL, Racz MJ, Jones RH, et al. Predictors of mortality for patients undergoing cardiac valve replacements in New York State. Ann Thorac Surg 2000;70:1212-18.

5. lung B, Baron G, Butchart EG, et al. A prospective survey of patients with valvular heart disease in Europe: The Euro Heart Survey on Valvular Heart Disease. Eur Heart J 2003;24:1231-43.

6. Feldman T, Foster E, Glower DD, et al, EVEREST II Investigators. Percutaneous repair or surgery for mitral regurgitation. $N$ Engl J Med 2011;364:1395-406.

7. Lim DS, Reynolds MR, Feldman T, et al. Improved functional status and quality of life in prohibitive surgical risk patients with degenerative mitral regurgitation after transcatheter mitral valve repair. J Am Coll Cardiol 2014;64:182-92.

8. Lang RM, Bierig M, Devereux RB, et al, Chamber Quantification Writing Group; American Society of Echocardiography's Guidelines and Standards Committee; European Association of Echocardiography. Recommendations for chamber quantification: a report from the American Society of Echocardiography's Guidelines and Standards Committee and the Chamber Quantification Writing Group, developed in conjunction with the European Association of Echocardiography, a branch of the European Society of Cardiology. J Am Soc Echocardiogr 2005;18:1440-63.

9. Nagueh SF, Appleton CP, Gillebert TC, et al. Recommendations for the evaluation of left ventricular diastolic function by echocardiography. J Am Soc Echocardiogr 2009;22:107-33.

10. Park HS, Naik SD, Aronow WS, et al. Differences of lateral and septal mitral annulus velocity by tissue Doppler imaging in the evaluation of left ventricular diastolic function. Am J Cardiol 2006;98:970-2.
11. Ommen SR, Nishimura RA, Hurrell DG, et al. Assessment of right atrial pressure with 2-dimensional and Doppler echocardiography: a simultaneous catheterization and echocardiographic study. Mayo Clin Proc 2000;75:24-9.

12. Onorati F, Santini F, Dandale R, et al. Functional mitral regurgitation: a 30 -year unresolved surgical journey from valve replacement to complex valve repairs. Heart Fail Rev 2014;19:341-58.

13. Taramasso M, Denti $P$, Buzzatti $N$, et al. Mitraclip therapy and surgical mitral repair in patients with moderate to severe left ventricular failure causing functional mitral regurgitation: a single-centre experience. Eur J Cardiothorac Surg 2012;42:920-6.

14. Whitlow PL, Feldman T, Pedersen WR, et al., EVEREST II Investigators. Acute and 12-month results with catheter-based mitral valve leaflet repair: the EVEREST II (Endovascular Valve Edge-to-Edge Repair) High Risk Study. J Am Coll Cardiol 2012:59:130-9.

15. Mauri L, Foster E, Glower DD, et al., EVEREST II Investigators. 4-Year results of a randomized controlled trial of percutaneous repair versus surgery for mitral regurgitation. J Am Coll Cardiol 2013;62:317-28.

16. Maisano F, Franzen $\mathrm{O}$, Baldus $\mathrm{S}$, et al. Percutaneous mitral valve interventions in the real world: early and 1-year results from the ACCESS-EU, a prospective, multicenter, nonrandomized post-approval study of the MitraClip therapy in Europe. J Am Coll Cardiol 2013;62:1052-61.

17. Wan B, Rahnavardi M, Tian DH, et al. A meta-analysis of MitraClip system versus surgery for treatment of severe mitral regurgitation. Ann Cardiothorac Surg 2013;2:683-92.

18. Conradi L, Treede H, Rudolph V, et al. Surgical or percutaneous mitral valve repair for secondary mitral regurgitation: comparison of patient characteristics and clinical outcomes. Eur J Cardiothorac Surg 2013;44:490-6.

19. Swaans MJ, Bakker AL, Alipour A, et al. Survival of transcatheter mitral valve repair compared with surgical and conservative treatment in high-surgical-risk patients. JACC Cardiovasc Interv 2014;7:875-81. 